\title{
coletânea de excertos sobre polêmicas literárias recentes
}

Apresentação: Laura Penna Alves e Emmanuel Santiago*
Retomamos aqui duas polêmicas literárias recentes, correndo um duplo risco: primeiro porque, como já dito no Editorial, o adjetivo "literário" se aplica a poucos momentos dessas polêmicas; segundo, porque a percepção de que algo seja recente, para o leitor de hoje, uma revista de de nos apropriar desses discursos recentemente vethos e propor sobre eles um olhar fora do calor da hora mas que mantivesse o tom do momento em que foram publicados. Segue então a tentativa de trazer um pouco de literatura para o debate e narrar duas histórias já conhecidas a partir excertos selecionados com a finalidade de tornar evidente a distância entre a maioria das intervenções e as reflexões que abarcassem os aspectos propriamente literários dos objetos discutidos. Antes de narrá-las, observemos que selecionar um texto, recortá-lo e transpó-lo para outro momento enunciativo 
é, necessariamente, algo que exige uma inevitável descontextualização. Um enunciado - entendido como ato texto que lhe confere um sentido especifico. No entanto não havendo nada que contradiga o excerto dentro da nanidade textual de que foi retirado, ele pode ser pens do como significativo em si mesmo, assim como penaso das citações acadêmicas, que preservam algo de se sentido original e adquirem novas nuances no texto em que são inseridas.

\section{Prêmio Jabuti 2010}

Vamos então a nossa reenunciação interessada. Assim como na fábula "A lebre e a tartaruga", atribuíd a Esopo e recontada por la Fontaine, aqui temos um competição que contrariou as expectativas daqueles
que a acompanhavam de perto. Em novembro de 2010, que a acompanhavam de perto. Em novembro de 2010 entrevista à Folha de S. Paulo a retirada da editora do prêmio Jabuti, o mais antigo do país, organizado pel categria melhorromance, Se eufechar os onhou agocategoria de melhor romance, Se eufechar os olhos agora, de Edney Silvestre, publicado pela Record, ficou em ficção, perdendo para uma publicação da Companhi das Letras - Leite derramado, de Chico Buarque -, segundo lugar na categoria vencida por Edney Silvestre. A premiação daquele ano teve a legitimidade de sua decisão questionada publicamente, mas, ao contrário do que se espera ocorrer em premiaçố literàrias, essa indagação não se deu em torno do mérito do livro ganhador, prescindindo de reflexões sobre os romances.

Na fábula de Esopo a tartaruga desafia a lebre para uma corrida e esta, segura de sua superioridade, tira um cochilo que the traz a derrota. A tartaruga, contando com te, alcança a inesperada vitória. A exemplo da lebre

128 romance de Edney Silvestre acabou não comprovando seu favoritismo, pressuposto no título de melhor ro mance, deixando escapar a vitória na fase mais imporde ficção do ano e na qual são inclú́das no júri pessoas ligadas a instituições do setor livreiro, como o Sindicato Nacional dos Editores de Livros (SNEL), a Associação Nacional de Livrarias (ANL) e a Associação Brasileira de Difusão do Livro (ABDL). A partir dessa analogia com a fábula, organizamos os excertos que alimentaram polêmica, de modo a renomear as assinaturas de algumas intervenços a que explicitam um tipo de engajamento em disputas fundamentalmente de mercado. Nessa comparação, a separaçăo entre lebre e tartaruga realiza a leitura dos excertos como cortina de fumaça criada para mascarar os interesses puramente comerciais da polêmica e fazer-nos acreditar que há, de fato um vencedor e um perdedor.

No entanto, na charge "A corrida", fazemos outro padessa disputa a discussão lierária é a grande lebre por excesso de confiança em sua força e astúcia. A discussão em torno do Prêmio Jabuti de 2010 não en volveu o questionamento quanto ao mérito artístico do livro ganhador e prescindiu de uma reflexão mais acurada sobre os romances em disputa. Os represen tantes comerciais protagonizaram o debate no espaço dos jornais e se concentraram em torno das regras e do funcionamento da premiação, ou seja, do modo de funcionamento de um momento estratégico da vendagem e distribuiçáo dos livros. Agindo de modo previsível, que surpreende é a naturalização com que aqueles que poderiam participar dessa polemica de modo distinto não se interessaram pela discussão sobre o valor literário dos romances. Temos assim, nessa outra apropriação da fabula, dois competidores simultaneamente vencedores e perdedores. Vencedores porque garantoras, e perdedores porque não despe grandes edcomo objetos literários, e sim como mercadorias que compõem a exposição espetacular de uma briga comercial. Figuramos então duas tartarugas correndo, onde poderíamos ter duas lebres dormindo.

\section{Caçadas de Pedrinho e o Programa Nacional Bibliote} ca da Escola (PNBE)

A segunda polêmica por nós relembrada também teve início em 2010, quando o Conselho Nacional da Educação (CNE) emitiu um parecer que apontava, entre outras coisas, a necessidade de uma nota explicativa no livro Caçadas de Pedrinho, de Monteiro Lobato, que integra a lista do Programa Nacional Biblioteca da Escola (PNBE), responsável pela distribuição gratuita Ivros para o Ensino Fundamental e Medio. Esta foi a solução encontrada para responder a uma denúncia, feita Ouvidoria da Secretaria de Politicas de Promoção d gualdade Racial (Seppir), de que o MEC estaria distripressõ rasistas, o que contradicos com teor e exdessa mesma secretaria Extrapolando esses espaços institucionais, a polâmica se expandiu para revistas, jornais, sites e blogs. Contudo, é difíil separar os contendores em contrários ou favoráveis aos parecers, até porque muitas da falas demonstraram que estes não foram lidos, ou lidos apressadamente. Por outro lado, isso nos facilita prosseguir em outra narrativa econtá-la a partir da passagem da Odisseia em que Ulisses, ao sair do Hades, recebe uma visita de Circe, que $o$ alerta para a ilha das sereias e o perigo que sua embarcação correria naquela regiáo. Sob os conselhos da deusa, Ulisses passa por esse mar amarrado ao mastro por seus marinheiros, que punham cera no ouvido para também não se atirarem em direção a essas criaturas de canto fatalmente sedutor, mas que repousam sobre carniça. Assim, relembramos o mar quase univoco de falas institucionais burocráticas que colocaram criam, nesse caso, tanto o dogmono ereia quanto as reflexões que operaram como cordas ceras e não permitem que os tripulantes se transformem em vítimas de qualquer espécie.

trajeto de Ulisses é regido por um Deus ex machina mercado, protegidos e alimentados ininterruptamente por diferentes governos, e que parecem ter criado as
condições para esse debate. É necessário lembrar que, atualmente, a escolha dos livros didáticos e paradidáticos que integram a lista do PNBE ocorre unicamente entre editoras e governo federal, sendo instituiçõos pecisão e, portanto, prejudicados em sua autonomi pedagogica. Ora, mas se a verticalização das decisõe sobre o ensino tem desfavorecido a atividade pedagogica, ela vem a calhar aos interesses editoriais. O MEC maior comprador de livros do Ocidente, sendo o mercado infantojuvenil, graças a isso, consideravelmente Há assim um uso do dinheiro público voltado para beneficio de poucas editoras e que prioriza o objeto vro em detrimento, principalmente, daqueles que dão sentido pedagógico a ele. Isso fica claro, no caso em questão, com a lógica lucrativa de resolução dos con litos por nota explicativa, nota de rodapé, manual de explicação etc.

Pois bem; desse mar de interesses privados surgem melodias das quais queremos fugir porque as julgamos sectárias. Estas são tanto melodias que desencorajam o enfrentamento de problemas que nosso tempo coloca ao texto literário, tal como o problema complexo da apropriação literaria de estereotipos depreciativos do negro - e tambem de outros grupos que sofrem com o preconceito - em livros com finalidade pedagógica, quanto canços paternallstas que parecem confund a literatura com uma espécie "mágica" de documento, mo indutora de um comportamento determinado. primeiro caso, vimos a defesa de uma "alta literatura" 
que transcenderia aspectos tidos como de menor imà dimensão simbólica do de vista, uma espécie de dispensabilidad de uma discussão, por princípio, sem legitimidade de existência. No segundo caso, a taxação de um livro como racista. sem a discussão de seus critérios de julgamento, a ausência de justificativas que partissem de experiências pedagógicas concretas $\mathrm{e}$, por fim, a sugestão de probição de sua compra por parte do Estado podem nos fazer voltar a uma especie de index, pois empregam expedientes de exclusáo muito parecidos com a política pouco democrática do governo federal.

Nesse sentido, por melhores que sejam as intençõe em pautar as questões étnico-raciais, eles sempre so relativas à política e ao poder. Ao tentar impor uma relativas à política e ao poder. Ao tentar impor uma
aceitação imediata das políticas de reparação, temos,

inclusive, a dificultação do surgimento de formulacões mais eficazes criadas e aplicadas localmente. Esquecendo a submissão geral a um sistema educacional verticalizado, os participantes da polêmica pareceram "comprar" as regras do jogo e querer apenas substituir um controle por outro. Por outro lado, desagrado em relação ao livro Caçadas de Pedrinho náo deveria ser tratado como opiniáo perigosa a ser eniminada, mas como posiçăa que precisa ser debatium esforço de representatividade entre aqueles que supostamente bate ao racismo. Optando assim por fugir de imperativos éticos que, historicamente, jà acenderam muita fogueira para se queimar livros e de imperativos estéticos que desprezam o cultivar silencioso de outras chamas, recontamosessa polênicaporme a devozes que contribuiram, como ceras e cordas, para a fuga de

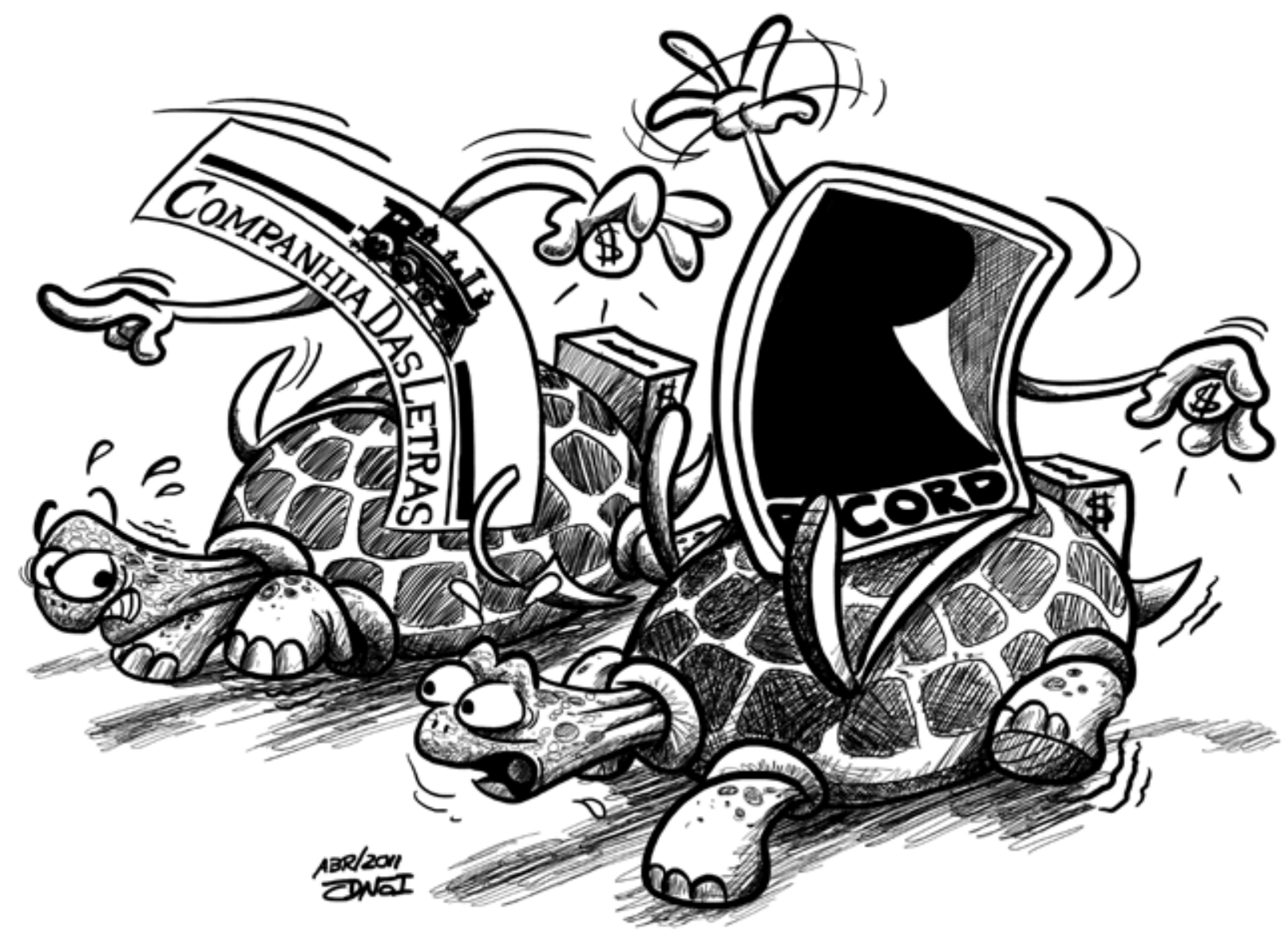


Tartaruga n. 2 leitores. Não fiz - nem me caberia - nenhum comentario púb ico sobre a póémica
do Jabuti (...). Por isso mesmo, só posso Jementar que, numa discussão em nome

\section{Tartaruga n. 1}

"Não estou aqui para defender a excelência dos meus romances. Também já compreendi que, para muitos, popular sanhe prêmios literários." (Chico Buarque, em e-mail para 0 Globo, $13 \mathrm{dez}$. 2011 )

\section{Organizadores do prêmio}

"No ato da inscrição das obras que concorreram ao Prêmio Jabuti 2010 - que este ano, a propósito, teve recorde de inscritos -, todos
os participantes declararam conhecer o regulamento da premiação.

(Câmara Brasileira de Livros - CBL, em "Nota de esclarecimite de 2010", 13 nov. 2010) de ética, respeito, delicadeza e cultura, seja gratuitamente atacado por um dono de uma poderosa editora "concorrente", que bem sabe que nós autores - ainda mais mercado surpreendentemente tão hostil."

(Edney Silvestre, "Somos o elo mais fraco neste mercado hostil", Folha de S. Paulo, 28 nov. 2010

\section{SOLIDÁRIO À TARTARUGA N. 1}

“(...) vi esse manifesto ['Chico, devolve o ' (damilia com Deus pela Liberdade expressando-se de forma verbal."

(Caetano Veloso, "A revolta do quelônio", O Globo, 29 nov. 2010)

\section{Patrocinador da Tartaruga n. 1}

"Se a cada derrota um partido político abandonar o Congresso, ou dizer 'assim não brinco mais de democracia', para onde irão nossas instituições, qual a possibilidade que teremos de discutir e criar novas regras, em atitude de respeito aos que pensam diferentemente?

respe

Atribuir a vitória de "Leite Derramado" à simpatia do escritor pela candidata vencedora das últimas eleiçōes, poucos dias após a realização destas, é apenas mais um capítulo da história política brasileira recente (....). Não discutimo

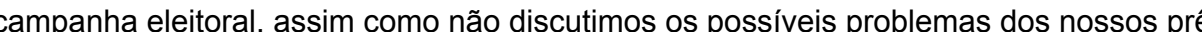
mios literários. Coincidência?"

(Luiz Schwarcz, editor da Cia. das Letras, "Quem garfou Edney Silvestre? - ou como se discute um prêmio literário

M COMPETIDOR FORA

DA COMPETIÇÃ̃O

"Prêmio literário 'Jabuti': a) anda devagar b) prestigio só dentro do casco (in-

(Paulo Coelho, via Twitter)

\section{Patrocinador da Tartaruga $\mathrm{n}$.}

"Esse prêmio, do jeito que está sendo disputado, podePorque não tem absulustán. Ou do Sivio santos

$$
\text { Porque não tem absolutam }
$$

Fui apenas o menino da fábula que gritou que o rei está nu. Não quero ser alfaiate de trajes reais, deixo isso para os encarregados de organizar a premiac̃a isso percebe Schwarcz que a atitude que tomei prima pela transparência e lisura. Tenho mais a fazer do que discutir remuneração de jurados ou custos de festas, como propõe ele, para desviar o foco do debate.

o momento que ele tem essa segunda etapa, na qual você reûne os três primeiros lugares, eles vão para um voto entre os associados, um voto que não é atribuído ao mérito, porque nenhum dos associados terá lido aqueles livros. Se algum leu, foi o seu, e acaba sendo um concurso de beleza, passa a ser um voto de simpa-

(Entrevista de Sergio Machado, presidente do Grupo Record, à Folha de S. Paulo, 14 nov. 2010)

\section{Advogada" da Tartaruga n. 2 no processo}

"Eu acho isso um sintoma da nossa pobreza cultural, da nossa caipirice. No Canadá existe uma situação muito parecida, mas não acontece nada disso. Você tristo Leonard Cohen, que e o grande "lyricist" " lenacional, que tem quatro ou cinco romances, vários livros de contos, ele nunca teve que ganhar prêmio no Canadá, apesar de ser um ídolo nacional." Entrevista de Luciana Vilas Boas, diretora editorial
do Grupo Record, à Folha de S. Paulo, 14 nov. 2010).

\section{Autor do abaixo-assinado:}

\section{"Tartaruga n. 1 devolve o Jabutil"}

"Me sinto mal ao ler as barbaridades que a petralh da escreve por lá, dirigidas a você [Reinaldo Azevedo] quando 0 alvo deveria ser a minha pessoa. Li até um acusac̃o de que eu não existo e seria apenas um pseudônimo seu".

Anderson Santana, autor da petição on-line "Chico, devolve o Jabuti", via blog de Reinaldo Azevedo)"

\section{Lider dos opositores à Tartaruga n 1}

"O editor escreve um artigo no caderno 'llustríssima', na Folha deste domingo.
Tropeça várias vezes: na tese, no mérito até no subjuntivo - pelo visto, o artigo não foi enviado a tempo a um dos revisores de sua empresa. Vamos lá. Ele segue em vermelho. Eu vou de azul."

(Reinaldo Azevedo, via blog) 
ESTE É O TAMANHO MÁXIMO QUE A IMAGEM ALCANÇA MANTENDO A RESOLUÇÃO NECESSÁRIA PARA IMPRESSÃO COM QUALIDADE (270 DPI)
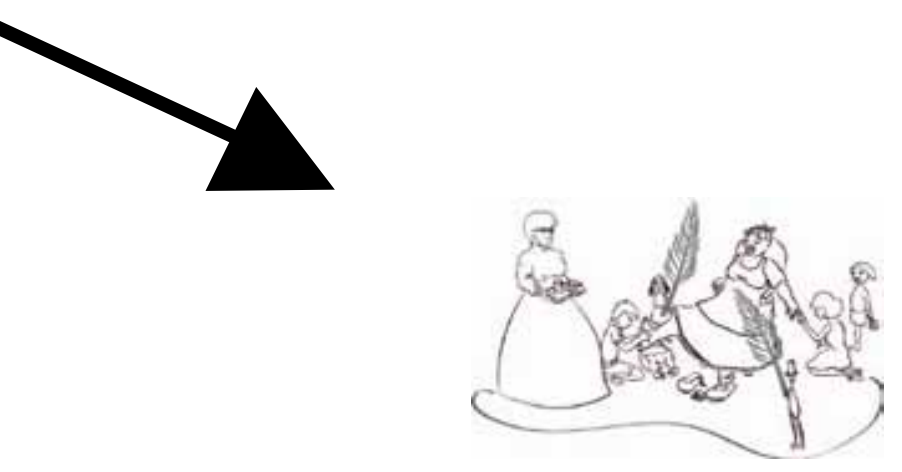
"Não há veto e não há censura na decisão do CNE. Há esclarecimento e orientação. Quem se op̃e a isto parece não compreender que todo s (Maria Izabel Azevedo Noronha, presidente da Apeoesp têm direito à informação correta."

"A academia, na linha das suas conviç̧ões democráticas, rejeita qualquer tipo de censura e entendeu a manifestação do Conselho como uma forma de censura."

(Marcos Vinícios Vilaça, presidente da Academia Brasileira de Letras - ABL, em declaração à reportagem "Livro de Monteiro Lobato é liberado para ser usado em sala de aula")

"As expressões que o livro contém são expressões de um conteúdo forte mente preconceituoso e que precisam de tratamento explicativo na sala de aula pra que não se ofenda a autoestima das crianças e dos leitores."

(Eloi Ferreira de Araújo, ex-ministro-chefe da Seppir, em declaração à reportagem "Livro de "Wonteiro Lobato é liberado para ser usedo em salo de aula" ")

A CERA E O MASTRO

“É triste perceber que, na opinião da maioria da sociedade, o racismo não é tão perigoso como o nazismo, tão abom nável como a pedofilia, tão ofensivo como a simples invasão de privacidade." (Alberto Mussa, “Me convençam”, Jornal Literário Rascunho)

"Como os antigos diziam que quem paga a música escolhe a dança, talvez se acredite hoje ser correto que quem paga o livro escolha a leitura que dele se vai fazer. A situação atual tem sua (triste) caricatura no lobo de Chapeuzinho Vermelho que não é mais abatido pelos caçadores, e pela dona Chica-ca que não mais atira um pau no gato-to. Muda-se o final da história e re-escreve-se a letra da música porque se acredita que leitores e ouvintes sairão dos livros e das cançōes abatendo lobos e caindo de pau em bichanos. Trata-se de uma ideia pobre, precária e incorreta que, além de considerar as crianças como tontas, desconsidera a função simbólica da cultura."

Um bom leitor de Lobato sabe que Tia Nastácia encarna a divindade criadora do Sítio do Picapau Amarelo. Ela é quem cria Emília, de uns trapos. Ela é quem cria o Visconde, de uma espiga de milho. Ela é quem cria João Faz-de-Conta, de um pedaço de pau. Ela é quem "cura" os personagens com suas costuras ou remendos, quem conta as histórias tradicionais, dentes no Brasil dessa época. Não é um insulto, é a triste constatação de uma vergonhosa realidade histórica."

136 (Marisa Lajolo, "Governo Lula censura Lobato", Sibila)
"Décadas se passaram. Expressōes que não eram consideradas ofensivas, hoje são. Mas, em se tratando de Monteiro Lobato, de um clássico brasileiro da literatura infantil, nós só temos que contextualizar, advertir e orientar sobretudo o professor sobre como lidar com esse tipo d

(Fernando Haddad, ministro da Educaçāo, em declaraçāo à reportagem "Livro de Monteiro Lobato é liberado para ser usado em sala de aula")

Me parece evidente que as aulas de leitura são fundamentais para a formaçâo de leitores. Mas eu năo sei ate que ponto as crianças devem ser obrigadas a ler os cânones. Recentemente houve uma polêmica em torno de um livro do Monteiro Lobato, por causa das expressões racistas que ele usa para se referir a uma personagem negra. Sou contra censurar ou alacho que o Estado não deveria adotar livros com esse conteúdo filho negro, não gostaria que ele fosse obrigado a ler Monteiro Lobato na escola. Não gostaria de vê-lo exposto a este maltrato."

(Paulo Franchetti, Correio Popular de Campinas)

\section{O CANTO DA SEREIA E A VOLTA DAS METÁFORAS} BIOLÓGICAS

"Quando Monteiro Lobato escreve: 'Tia Nastácia, esquecida dos seus numerosos reumatismos, trepou, que nem uma macaca de carvão', o que ele faz e usar duas comparações, uma retirada do reino animal, para descrever a ação, e outra de elementos da natureza, para descrever a cor rápido em troncos, nove entre dez citarão o macaco. E Tia Nastácia, uma das personarens mais queridas e simpáticas da literatura brasileira, era uma senhora negra. Terá alguma etnia - ou qualquer outro grupamento humano - o privilégio de não poder ser exposta ao cômico ou ao ridículo? o curioso é que quase todas as chamadas minorias afirmam querer ser reconhecidas como o que são, mas quando o são, acham-se ofendidas."

(Alexei Bueno, "Quem é racista", Jornal Literário Rascunho)

elhor: defendo que sejam suprimidas ou reescritas todas as passagens racistas dos textos infantis de Monteiro Lobato. Ou no minimo - a exemplo do que se faz com o fumo - que se advirta: 'Este livro contém pensamentos e expressões que configuram discriminação racial'."

(Alberto Mussa, "Me convençam", Jornal Literário Rascunho)

"Sendo assim, é necessária a indução dessa política pública, pelo Governo do professores que sejam capazes de lidar com esse tipo de situasãa no cotidiano escolar.

A obra Caçadas de Pedrinho só deve ser utilizada no contexto da educação escolar quando o professor tiver a compreensão dos processos históricos que
geram o racismo no Brasil."

(Nota Técnica CNE/CEB n $\left.n^{\circ} 044 / 2010\right)^{5}$ 
5 Disponivel em: <http:///portal.mec. govo.brindex.php??option=com_content \&view=articlesid=12992:-diretrizes-para-a-educacao-basica\&catid=323:-0rgaosvinculadoss. Acesso: 13 jan. 2011.

6 Disponivel em: <http://apeeesp.org.brr/lipping/monteirolobato.htm//> Acesso: 25 fev. 2011.

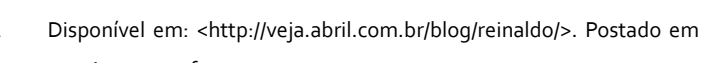

nov. 2010. Acesso: 15 fev. 2011.

2 Postado em 30 nov. 2010. Acesso: 15 fev. 2011.

Disponivelem: shtp:///g-globo.com/vestibular-e-educacao/noticia/2010 Postado em 5 out. 2010. Acesso: 20 nov. 2010.

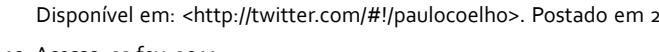
2010. Acesso: 23 fev. 2011 .

8 Disponivel em: <http:I/rascunho.rpc.com.brindexx. Postado em nov 2010. Acesso: 12 fev. 2011. 9 Disponivel em: <http://www.sibila.com.brrindex.php/mix/1686-governo 